\title{
Economic Realities and Consequences of the COVID-19 Pandemic_-PART II: The Economy and Fiscal Policy
}

Fernando Martin, Research Officer and Economist

T he measures to combat the COVID-19 pandemic will substantially reduce economic activity for an uncertain period. In Part 1 of this essay I discussed the impact on financial markets and the Federal Reserve's response. In Part II, I focus on the broader economy and the fiscal policy response.

The economy is showing both positive and negative reactions to shutdown measures.

As of March 2020, the U.S. economy has almost certainly entered a recession. Market estimates of the output contraction in the second quarter of 2020 range from 10 percent to 30 percent at annual rates. Similarly, the unemployment rate is expected to rise sharply, going from 3.5 percent in February to anywhere between 6 percent and 13 percent during the second quarter.

The following back-of-the-envelope calculations put these numbers into perspective: Gross domestic product (GDP) was about $\$ 21$ trillion dollars in 2019. If a third of the economy shuts down for a month, this implies around a $\$ 600$ billion loss in output. The current labor force is about 165 million workers; if the unemployment rate climbs to 10 percent this would translate to roughly 11 million new unemployed workers.

How is the economy coping with the shutdowns? On the positive side, large sectors of the workforce are telecommuting; basic services, such as utilities, are fully operational; and many transactions and interactions are being conducted online. Importantly, these are all interrelated. For example, online transactions work because internet and postal services are running.

On the negative side, the health care sector is at risk of being overwhelmed and the health care policy response has been slow due to a lack of "nimbleness": a combination of the barriers placed by regulation and a dependence on a fragile global supply chain for surgical masks, tests, and ventilators. There is also a shortage of qualified labor and treatment installations.

The widespread recognition of our present dependence on imported goods as undesirable means that, in the future, the production of some medical essentials will probably be shifted domestically and that a health care strategic reserve will likely be built. If past experience is any indication, however, government regulation of the health care sector may actually increase.

Ordinary government stimulus is designed to get people spending and increase economic activity. The unusual nature of the current crisis, in which we must discourage much of the usual economic activity, means that policymakers must get a bit more creative with social insurance and fiscal policy more generally. On March 23, the CARE Act was signed into law, consisting of a $\$ 2$ trillion dollar fiscal stimulus package. The package is mostly a combination of direct assistance to households (e.g., unemployment insurance expansions, tax deferrals, and transfers) and loans to businesses. As a reference for the magnitude of this package, the fiscal cost of the 2009 American Recovery and Reinvestment Act was roughly $\$ 800$ billion.

How should this new expenditure be financed? Experience (e.g., wartime) and theory has taught us that temporary shocks such as this one should be financed with debt, rather than current taxation. This allows the costs of fiscal intervention to be spread over time.

As in the Financial Crisis of 2007-09, there is currently a high demand for safe assets, including Treasury debt. This flight-to-safety works in the Treasury's favor, keeping interest rates on government debt low, without further Fed intervention.

The big economic question is whether this will be a $\mathrm{V}$-shaped recession or protracted. Many sectors will likely recover quickly, as most of the current contraction comes from workers staying home rather than declines in capital or productivity. But we do not know how well small- and 
medium-sized businesses can survive a prolonged shutdown. A quick recovery scenario also assumes government policy prevents businesses from becoming impaired or going bankrupt due to lack of revenue.

International trade, especially with China, as well as global supply chains are likely to be seriously reassessed. International labor mobility may be severely impaired. Though the long-run effects remain uncertain, these factors may contribute to lower output. The economy as a whole would essentially be trading off productivity for insurance, which may be a beneficial choice. Another factor that could slow down the recovery is the (reasonable) expectation of a second wave of infections in 2021. 